\title{
An Empirical Analysis of Manufacturing Overhead Cost Drivers
}

\author{
Rajiv D. Banker \\ Carlson School of Management \\ University of Minnesota \\ Minneapolis, MN 55455 \\ Gordon Potter \\ School of Hotel Administration \\ Cornell University \\ Ithaca, NY 14853 \\ Roger G. Schroeder \\ Carlson School of Management \\ University of Minnesota \\ Minneapolis, MN 55455
}

Submitted April 1992 to Journal of Accounting \& Economics

\section{Author Note}

Helpful comments and suggestions by Jerry Zimmerman (the editor), Anthony Atkinson and Patricia C. O'Brien (the referees), and seminar participants at University of California-Irvine, Carnegie Mellon University, Harvard University, University of Minnesota, New York University, Oklahoma State University, University of Wisconsin-Milwaukee, the 1992 Management Accounting Research Conference, and the 1992 Midwest and Annual Meetings of the American Accounting Association are gratefully acknowledged. 


\begin{abstract}
Empirical validity of the claim that overhead costs are driven not by production volume but by transactions resulting from production complexity is examined using data from 32 manufacturing plants from the electronics, machinery, and automobile components industries. Transactions are measured using number of engineering change orders, number of purchasing and production planning personnel, shop- floor area per part, and number of quality control and improvement personnel. Results indicate a strong positive relation between manufacturing overhead costs and both manufacturing transactions and production volume. Most of the variation in overhead costs, however, is explained by measures of manufacturing transactions, not volume.
\end{abstract}

\title{
Keywords
}

manufacturing overhead, overhead costs, cost drivers, transactions, production complexity

JEL classification: $M 40 ; L 23 ; L 60$ 


\section{An empirical analysis of manufacturing overhead cost drivers}

\section{Introduction}

Recent literature in manufacturing strategy and management accounting has argued that production and support activities other than direct labor drive manufacturing overhead costs. Miller and Vollmann (1985) state that the real driving force behind manufacturing overhead costs is not production volume but transactions dealing with logistics, balancing, quality, and change. Cooper and Kaplan (1987) and Johnson and Kaplan (1987) suggest that many of the transactions that drive costs are determined by the complexity of plants' operations. Hayes and Clark (1985) indicate that production complexity increases with the number of product lines, the variety of flow patterns, and number of inventory locations. Empirical analysis of manufacturing overhead costs of 37 plants of one firm by Foster and Gupta (1990), henceforth FG, however, provides only limited evidence of association of overhead with transactional measures of production complexity. In this paper we present evidence about the impact of transactions on the overhead costs of manufacturers.

If overhead costs are generated by transactions not directly proportional to production volume but these costs are assigned to products based on measures of volume, then product costs may be distorted. Cooper and Kaplan (1987) and Shank and Govindarajan (1988) warn that one consequence of distorted product costs is the likelihood that manufacturers will over-emphasize less profitable product lines. To avoid these distortions, they recommend the use of activitybased costing $(\mathrm{ABC})$ systems based on multiple transactional drivers other than volume. Johnson (1988) suggests that understanding how transactional variables relate to resource consumption 
for support activities aids in the identification of areas for process and product improvement, cost reduction and more generally helps pinpoint sources of competitive value. Furthermore, Cooper and Kaplan (1991) state that identifying transactional cost drivers is important because they capture the underlying scientific and engineering laws governing the production process, and help generate more accurate and useful flexible budgets.

These potential benefits claimed for costing systems based on transactional cost drivers underscore the need for an empirical investigation of the possible existence of multiple cost drivers. If cost drivers other than volume are not significant, then the benefits of switching from a volume-based product costing system are likely to be minimal. Thus, a necessary condition for an economic demand to arise for an $\mathrm{ABC}$ system is that some overhead costs are generated by transactions not directly proportional to production volume. However, this condition is not sufficient for prescribing the use of an ABC system. Agency issues, data problems and competitive considerations can result in traditional volume-based costing systems being preferred over an ABC system. ${ }^{1}$

Thus, the first step in empirically evaluating the need for $\mathrm{ABC}$ systems is to examine if factors other than volume drive overhead costs. Empirical evidence from the manufacturing sector, however, does not document a strong relation between overhead costs and measures of production complexity after controlling for volume. Foster and Gupta's (1990) pioneering study examined the behavior of overhead costs in 37 plants of a U.S.-based international electronics manufacturer. Their method of analysis was to examine the extent of correlations, and partial

\footnotetext{
${ }^{1}$ For instance, unionized plants may seek to overstate the impact of direct labor on product cost to reduce the incentives for labor unions to demand higher wages. In a related vein, Hiromoto (1988) writes that many Japanese manufacturers purposely allocate overhead costs based on direct labor to strengthen the incentives for managers to replace direct labor with automated machinery, consistent with their company's long-term strategy. Moreover, Banker and Potter (1993) identify conditions under which the expected profits of rival firms in a duopoly are greater when they use traditional volume-based costing systems than when they use ABC systems.
} 
correlations, between measures of manufacturing overhead and variables categorized by their posited relation to production volume, complexity, and efficiency. Thirty-four potential cost drivers were investigated. Foster and Gupta concluded (p. 310):

There are two major sets of findings. First, there is a strong empirical association between volume-based variables and manufacturing overhead levels across facilities. Second, after controlling for scale differences, there is not a strong association between complexity or efficiency variables and manufacturing overhead levels across the 37 facilities.

In a study of the airline industry, Banker and Johnston (1993) examined the effects of volume and operating strategy on the costs of 28 carriers over the five year period from 1981 to 1985. Their method of investigation differed from that of Foster and Gupta (FG). They used multiple-regression analysis of pooled time-series and cross-sectional observations to estimate the relation between overhead and cost drivers. They found that variables capturing product diversity and process complexity were significantly related to costs for their sample of airlines. They found that output capacity and volume were also important cost drivers. Therefore, unlike FG, their results suggest that both volume and transactional variables are related to overhead costs.

We estimate the association between manufacturing overhead costs and measures of transactions and volume using data from 32 plants located in the United States. The plants in our sample represent firms in the electronics, machinery, and automobile components industries. Building on the transactions analysis of Miller and Vollmann, we examine the relation between overhead and shopfloor area per part, number of purchasing and production planning personnel, number of quality control and improvement personnel, and number of engineering change orders. We use direct labor dollars to measure volume. Our results indicate a strong relation between overhead and both production volume and transactions for this sample of plants. As 
such, the results provide evidence that manufacturing overhead costs are associated with transactions that are not directly related to volume.

The rest of this paper is organized as follows. The impact of volume and transactions on manufacturing overhead, and construction of measures of transactions are discussed in the next section. Our cross-sectional estimation model is described in Section 3. Potential differences in statistical inference that may occur from FG's use of partial correlation rather than multiple regression analysis are also discussed in this section. The results of our empirical analysis are described in Section 4. Concluding remarks are presented in Section 5.

\section{Overhead costs and manufacturing transactions}

There are few formal models describing the behavior of manufacturing overhead costs. Drucker (1963) was one of the first to note that overhead costs vary with the number of transactions, not the number of units produced. Miller and Vollmann (1985, p. 144) also state that the primary drivers of manufacturing overhead costs are transactions which are not directly related to volume:

... in the 'hidden factory' where the bulk of the manufacturing costs accumulates, the real driving force comes from transactions, not physical products. These transactions involve exchanges of materials and/or information necessary to move production along but do not directly result in physical products.

They identify four types of transactions: logistical, balancing, quality, and change, which they hypothesize account for most manufacturing overhead costs.

Logistical transactions are incurred to receive and move materials in the plant. Examples of logistical transactions include materials handling and movement, receiving, requisitions, and stores activities. The greater the area over which batches of materials need to be moved and 
stored, the greater the demand for support resources to perform logistical transactions. Large work areas also reflect large work-in-process inventories which necessitate many logistical transactions (Miller and Vollmann, 1985, p. 156). Therefore, we use the average shopfloor area per part as the surrogate measure for logistical transactions.

Closely related to logistical transactions are balancing transactions. Balancing transactions deal with the coordination of production activities initiated to insure that the supply of materials, labor, and capacity equals demand. Miller and Vollmann offer planning for materials and labor and scheduling of machinery for production, as examples of balancing transactions. Purchasing and production planning personnel are required to deal with the many bills of material and production orders required in plants producing a variety of products (Cooper and Kaplan, 1987). Therefore, we use the number of purchasing and production planning personnel as the measure of balancing transactions. $^{2}$

Quality transactions are incurred by manufacturers to insure that goods are produced to customer requirements. Quality control transactions are incurred for inspection, rework, warranty repair, and for supplier and customer interface. As continuous improvement of quality becomes a major concern, quality improvement transactions are incurred for training, design engineering, and prevention activities (Deming, 1986). We use the number of personnel involved in quality control and improvement as the measure of quality transactions. This measure is chosen because it captures the transactions incurred for prevention as well as those incurred for inspection and rework. $^{3}$

\footnotetext{
${ }^{2}$ Number of product lines is an alternative overhead cost driver that reflects demand for more balancing transactions (Cooper and Kaplan, 1991). Empirical results we report in this paper are robust to the use of number of product lines as the measure of balancing transactions. All four transactional variables are statistically significant at the $5 \%$ level when the number of product lines is used as the measure of balancing transactions.

${ }^{3}$ We also obtained a measure of quality costs estimated by plant personnel based on inspection and rework costs. However, this measure was imperfect as it excluded internal costs of quality improvement and external costs due to
} 
Finally, change transactions are incurred to revise manufacturing systems for alterations in product or process design. Miller and Vollmann suggest that typical change transactions include the introduction of new raw material into a product, revision of material composition, and routing changes due to process alterations. Miller and Vollmann offer engineering change orders (ECO) as an example of change transactions. ECO document the initiation of product or process design changes. Therefore, we use ECO as the measure of change transactions.

Miller and Vollmann $(1985,143)$ acknowledge that overhead costs may be correlated with volume even though they are driven by a variety of transactions:

... the driving force behind most overhead costs is not unit output or direct labor. Overhead costs do usually correlate with unit outputs, but that does not mean that unit outputs 'cause' overhead costs.

For example, if purchasing is an activity that drives overhead, and more purchase transactions are necessary as the volume of production increases, then volume will be highly correlated with overhead. We control for volume effects by including direct labor dollars in our multivariate regression model. The inclusion of this variable helps insure that any documented effect of transactions on manufacturing overhead is not caused by volume.

Cooper (1990) and Cooper and Kaplan (1991) provide an alternative framework for understanding the behavior of manufacturing overhead costs. They state that product costs are driven by four types of activities: unit-level, batch- level, product-sustaining, and facilitysustaining. The demand for unit-level activities varies directly with the number of units produced. Examples include direct labor and direct materials. Batch-level activities occur each time a batch is processed. These activities include setups, material movements, and purchase orders. Product-sustaining activities are undertaken to enable specific products to be produced. 
Product and process engineering and engineering change orders are examples of these activities. Finally, facility-sustaining activities relate to plant management and maintenance of facilities. While we do not model transactions using Cooper and Kaplan's taxonomy, the variables we include can be recast in their framework. Our direct labor variable is a unit-level measure. Our measures of logistical and balancing transactions relate to batch-level activities, and engineering change orders reflect product-sustaining activities. The Miller and Vollmann framework does not suggest any facility-related activities, and we do not include such a measure in our principal model. We do examine the sensitivity of our results to facility-related variables, however, by including in our analysis the investment in property and equipment and the number of administrative functions undertaken at the plant.

\section{Estimation model}

\section{Cross-sectional analysis}

In this study we use cross-sectional data to examine the effect of transactions on manufacturing overhead costs. The primary benefit of cross-sectional analysis comes from variation in transactions across plants, as a time-series study of a plant (or very similar plants owned by one firm) is unlikely to reflect much variation in manufacturing practices and consequently in the mix of transactions. Sufficient variation in time-series data occurs only when a plant rearranges its processes, machinery, product mix, or workforce policies.

In a cross-sectional research design, there is a potential for spurious correlations to generate associations that are not based on causal relations. An improved design, if data were available for the same plants at another point in time, is a cross-sectional analysis of the changes in overhead costs in relation to changes in the hypothesized causal factors. An alternative 
research design is to examine time-series data for a plant spanning periods both before and after major changes in manufacturing configuration leading to large variation in the mix of transactions.

There are other limitations also in the use of cross-sectional data. Because the plant is the unit of analysis, some organizational functions, such as engineering, design, or purchasing, may not be conducted at some plants thus influencing the level of overhead costs for different observations. In our study we control for variation in administrative functions by including a variable that represents the number of functions conducted at the plant level. An additional caveat concerns the classification of costs into direct labor, direct materials, and manufacturing overhead costs. For instance, some labor functions may be classified as direct labor in one plant and as indirect labor in another. Because this measurement error adds noise to the dependent variable, there is a reduction in the power of the statistical tests.

\section{Multivariate regression compared to partial correlation}

Foster and Gupta estimated the association between costs and measures of production complexity and efficiency using correlation analysis after controlling for volume. Foster and Gupta chose correlation analysis because they did not deem it appropriate to specify a functional form relating the volume and transactional variables to manufacturing overhead (MOH) costs. They state (p. 311):

At this stage in research, little is known about exact functional relations or about how ... $\mathrm{MOH}$ cost drivers interact with each other. Correlation analysis is adopted in this paper. We view this approach as appropriate, especially given the small number of data points . . . Our analysis is more modest than an attempt to estimate an hypothesized $\mathrm{MOH}$ cost function for the 37 facilities of Electronics Inc. 
Their two-step partial correlation analysis involves regressing $\mathrm{MOH}$, and then a transactional variable, on a volume variable (revenues). The correlation between the residuals from the two equations is then computed. Both of these steps are linear operations. For econometric reasons outlined below, the multivariate regression analysis offers an approach that is conceptually superior to FG's partial correlation method. The FG procedure is equivalent to a bivariate linear regression of $\mathrm{MOH}$ on the volume variable and the transactional variable, after adjusting for differences in the number of degrees of freedom (Greene, 1993, p. 180). That is, implicit in FG's partial correlation analysis is the assumption of a bivariate linear cost function.

FG maintain, however, as we do, that multiple variables influence MOH costs simultaneously. Their implicit bivariate linear regression may be regarded, therefore, as a misspecified model due to omitted variables. If there is more than one transactional variable driving overhead costs, then we can show that the FG partial correlation test statistic is biased. [The detailed algebraic analysis is available from the authors. See also Goldberger $(1964,1991)$.] If the transactional variables are uncorrelated after controlling for volume, then the FG test statistic is biased downward and the null hypothesis tends to be not rejected even when many types of transactions significantly influence overhead costs. If the transactional variables are sufficiently highly correlated then the FG test statistic can be biased upward because part of the impact of the variable excluded from the bivariate regression implicit in FG is attributed to the included variable. We find that after controlling for volume there is little correlation between the transactional variables. In Table 8, we report empirical results using the FG partial correlation approach for our data. These results demonstrate that the FG approach does not provide the same inferences as those provided by multivariate regression. The multiple-regression approach provides unbiased and more efficient estimators of the relation between multiple transactional 
variables and overhead costs. For this reason, the multiple-regression analysis we employ in this paper is ex ante the preferred econometric approach.

\section{Loglinear model of overhead costs volume and transactional variables}

We specify the following multivariate regression model to estimate the relation between MOFI $(h)$, volume $(r)$, and transactional $\left(z_{k}\right)$ variables:

$$
h=B_{0} v^{\beta_{v}} \prod_{k=1}^{k} z_{k}^{\beta_{z k}}
$$

Taking the natural logarithm of Eq. (1) yields the following linear model:

$$
H=\beta_{0}+\beta_{v} V+\sum_{k=1}^{K} \beta_{z k} Z_{k}
$$

where the capital letters represent the natural logarithms of the corresponding variable $(\ln x ; x=$ $h, v, z)$ and $\beta_{0}=\ln \beta_{0}$. Tests concerning the significance of transactional variables in explaining the variation in overhead costs are conducted by examining the $\beta_{z k}$ coefficients. If overhead costs increase due to logistical, balancing, quality, and change transactions, then these coefficients should be positive. If overhead costs also increase with volume, then the $\beta_{v}$ coefficient should be greater than zero.

The multiplicative model reflects the notion that the impact of an increase in a transactional or volume variable on overhead costs $\left(\partial h / \partial z_{k}\right.$ or $\left.\partial h / \partial v\right)$ is greater when the levels of other variables are higher. Logarithmic transformation of the variables also reduces deviations from normal distribution for our sample data. The normality assumption is rejected at the $1 \%$ level for our overhead cost, volume, and all four transactional variables (FG report a similar finding). In no case is the normality assumption rejected at even the $5 \%$ level when we consider 
logarithmically transformed variables. While this loglinear formulation resembles a CobbDouglas type cost function, it is not intended to represent an economic cost function reflecting optimal allocation of resources given prices (Shephard, 1970). We choose this form because it is parsimonious, requiring the fewest number of parameters to be estimated given the volume and transactional variables, thus preserving degrees of freedom for our sample of only 32 plants. Most importantly, as we report in the next section, the test of linearity based on the Box-Cox transformation (Greene, 1993, p. 334) does not reject our loglinear model specification, but it does reject the linear additive model that represents an alternative parsimonious model.

\section{Empirical model}

\section{Sample}

The sample consists of 32 plants from the electronics, machinery, and automobile components industries. Sixty plants were initially randomly selected from the directory of manufacturing plants in these three industries. The plant manager of each plant was contacted by both letter and phone to solicit participation in the study. Forty-two plants agreed to participate in the study, of which twelve were visited in the initial phase of this study by members of the research team. The visits included a tour of the facility and interviews with the plant manager, plant accountant, and production personnel. Of the 42 plants in the original sample, eight were not willing to provide a detailed breakdown of their plant costs. An additional two plants are excluded from the analysis because of incomplete information about the independent variables used in our study. A comparison of plant size and industry for the 10 deleted observations with the 32 sample plants is presented in Table 1. While the sample plants appear to be smaller, median differences are not significant. Panel B reveals that half of the deleted observations are 
from the machinery industry, but the difference in industry representation is not statistically significant.

\section{Measures of manufacturing transactions volume}

We construct the following measures for manufacturing transactions corresponding to each of Miller and Vollmann's transaction types.

Transaction type Transactional variable

Logistical $\quad$ AREAPP $=$ square feet per part

Balancing PPPPER $=$ number of purchasing and production planning personnel

Quality QUALPER = number of quality control and improvement personnel

Change $\quad \mathrm{NECO}=$ number of engineering change orders

\section{Insert Table 1 Here}

Additional variables are constructed to control for differences in overhead costs due to volume, facilities, and industry. Direct labor dollars $(D I R L A B)$ is used as a measure of volume. The book value of plant and equipment $(P L T E Q P)$ is used as a control variable for facility-sustaining activities. DIRLAB and PLTEQP together also capture the substitution possibility between labor and capital investment. We also collected information on the administrative functions carried out at each plant. The following seven functions were identified: new product design/redesign, purchasing major materials, process engineering, direct receipt of customer orders, methods engineering, warehousing and distribution of finished goods, and production planning and scheduling. The variable $N A D M F N$ measures the total number of these functions performed at a plant. Finally, the dummy variables ACMPIND (automobile components industry) and MACHIND (machinery industry) are included to control for industry effects. 


\section{Descriptive statistics}

Table 2 presents descriptive statistics for the components of manufacturing costs. Panel A reveals that on average $\mathrm{MOH}$ comprise one-fourth of total manufacturing costs. Direct labor, on the other hand, is less than $10 \%$ of total costs. Direct materials account for the remaining twothirds of total manufacturing costs. The decile information indicates a wide range of relative cost components.

Insert Table 2 Here

Panel B presents the percentages of manufacturing cost components by industry. There is little variation in mean percentages across the three industries. Manufacturing overhead costs comprise approximately one-fourth of total manufacturing costs in each industry. Panel B also displays the average cost component percentages for the 37 plants of Electronics Inc. that are reported in Foster and Gupta. The average $\mathrm{MOH}$ percentage in their study, 39.1\%, is much higher than the average $M O H$ percentage for the electronics firms in this study, $26.4 \%$. In fact, the median $\mathrm{MOH}$ proportion in our sample is less than the first decile (not reported here) of the distribution of $\mathrm{MOH}$ for FG's sample. This difference suggests that the firm Electronics Inc. in the FG study is in the upper tail of the distribution of $M O H$ in the electronics industry.

Summary statistics are presented in Table 3. For most of the variables, the median value is much lower than the mean value. This is indicative of variables that are skewed to the right. As noted earlier, the normality assumption is rejected at the $1 \%$ level for all cost, volume, and transactional variables. Foster and Gupta document a similar distributional characteristic. The average number of purchasing and production planning personnel and annual engineering change 
orders are 23.8 and 424.3, respectively. The range of these variables is wide with the first deciles of 2 and 14 and ninth deciles of 74 and 1350, respectively. Overall, there is a great deal of variation in the independent variables. Panel B presents an industry comparison of the means and medians of these variables. No significant differences in medians across the three industries are indicated except in the case of $N E C O$, which are significantly lower in automobile components plants. The low number of engineering change orders for the automobile components plants is explained by noting that these plants are primarily used for assembly, not fabrication.

Pearson and Spearman correlations for the log transformed variables are presented in Table 4. Pearson coefficients are below the diagonal. The far left column documents the Pearson correlation between $\mathrm{MOH}$ and the predictor variables. All of the transactional variables are significantly correlated with $\mathrm{MOH}$. Some of the correlations with $\mathrm{MOH}$ can be compared to those in FG. Foster and Gupta report Spearman correlations with $\mathrm{MOH}$ of 0.85 and 0.83 for direct labor and investment in plant and equipment, respectively. Similar correlations for our study are 0.73 and 0.645 . Foster and Gupta also report a Spearman correlation between $M O H$ and NECO of 0.56 , it is 0.45 for our sample. There is also positive correlation between predictor variables. With the exception of $A R E A P P$, the transactional variables are correlated with each other. Note that the Pearson correlation of PPPPER and QUALPER is 0.822. PLTEQP and $D I R L A B$ also are highly correlated with a Pearson coefficient of 0.566 . These correlations suggest potential multicollinearity problems.

Insert Table 3 Here

Insert Table 4 Here 
Insert Table 5 Here

\section{Results}

\section{Principal results}

The regression results relating manufacturing overhead costs to transactions are presented in Table 5. Also presented are $F$-tests of the joint influence of the transactional variables on $\mathrm{MOH}$ after controlling for volume and industry effects. The regression in column (A) represents our principal model. In that regression the predictors explain about $83 \%$ of the cross-sectional variation in overhead costs. The inclusion of the four transactional variables significantly increases the explanatory power of the model $[p($ TRANSACT $)=0.0001]$. This indicates that not all of the explained variation can be attributed to volume effects. Each of the estimated transactional variables has the predicted positive sign. While the coefficient for $Q U A L P E R$ is not significantly different from zero, the coefficients for the remaining three transactional variables, $A R E A P P, P P P P E R$, and $N E C O$, are positive and individually significantly different from zero at the $1 \%$ level. The coefficient for volume, DIRLAB, also has a significant positive relation with overhead. This last result is consistent with prior research documenting that volume variables are strongly related to overhead. The intercept dummy variables for the industries are insignificant, suggesting that overhead costs are not different for the three industries after controlling for the volume and transactional variables.

The regression in column (B) reveals that the signs and statistical significance of the transactional variables do not change appreciably when the $D I R L A B$ variable is dropped from the model. In this case the transactional variables also capture most of the volume effect as the variation explained only drops from 0.827 to 0.774 . This can be compared to the adjusted $R^{2}$ of 
0.489 for the regression in column (C) that excludes the four transactional variables. Clearly transactions explain much more of the variation in overhead costs than that explained by volume alone. Note also the dramatic increase in the DIRLAB coefficient in column (C). This occurs as $D I R L A B$ picks up a portion of the effects attributed to transactions in the regression in column (A). With the misspecified model in column (C), it appears that $\mathrm{MOH}$ are proportional to $D I R L A B$ as the estimated coefficient $\hat{\beta}_{5}=0.904$ is not significantly different from one (see Noreen and Soderstrom, 1994).

The results for the model in column (D) which includes PLTEQP reveal that the inclusion of investment in plant and equipment has little incremental explanatory power. Adding PLTEQP also dampens the effect of DIRLAB on $M O H$. The regression in column (E) indicates that the number of administrative functions performed at the plant is positively and significantly associated with $\mathrm{MOH}$. The direction and significance of the relations discussed for our principal model in column (A), however, are robust to the above changes in model specification. Overall, the strength of the results suggest that the four types of transactions described by Miller and Vollmann can explain a large amount of the variation in manufacturing overhead costs. To assess the managerial significance of these results we consider a hypothetical plant that has the sample means for the values of the independent variables. When the transaction variables are reduced by one-fourth of their corresponding standard deviations, the predicted overhead costs based on model (A) decrease by $33.2 \%$, with AREAPP contributing a $10.4 \%$ reduction and PPPPER contributing a $16.5 \%$ reduction. This analysis suggests that the impact of these transactions on overhead costs is large both statistically and economically. 


\section{Sensitivity analysis}

To insure that the inferences are reasonable we examine the assumptions underlying our principal regression in column (A) of Table 5. Potential data problems are also examined. The results of these analyses are reported in Tables 6 and 7. A key assumption underlying the OLS model is that the error terms have an expectation of zero (i.e., the expectation of the dependent variable equals the specified parametric function of the independent variables) and that they have a constant variance (Goldberger, 1964; Greene, 1993). The statistical tests in Table 5 also rely on the assumption that the error terms are normally distributed.

We checked the OLS residuals for consistency with normality using the Shapiro- Wilk (1965) test designed for small samples. This test did not reject normality at conventional levels of significance. The least absolute error $(L A E)$ regressions in the third column of Table 6 also examines the robustness of our results (Koenker and Basset, 1978) to the distributional assumption for the error term.

The Glesjer (1969) test did not reject homoscedasticity at conventional levels $(p>0.20)$. White's general test for misspecification, however, rejected homoscedasticity ( $p=0.0001$ ). The fourth column in Table 6 presents White's (1980) adjusted standard errors and asymptotically chi-square distributed statistics to account for the unspecified variation from homoscedasticity.

A major concern is the extent to which the results are driven by the parametric structure imposed by our loglinear specification of the relation between overhead costs and the regressors. Therefore, we estimated the rank transform regression which provides approximations to unknown nonlinear relations between variables (Iman and Conover, 1979). ${ }^{4}$ These results are

\footnotetext{
${ }^{4}$ The rank transform regression may also be viewed as a multivariate extension of FG's Spearman partial correlation test.
} 
reported in the fifth column of Table 6 . The signs, relative magnitudes, and statistical significance of the key parameters in our model are generally consistent across the results reported in Table 6.

Insert Table 6 Here

We also conducted a Box-Cox transformation based test of our loglinear specification (Greene, 1993, pp. 334-335). For this purpose, the dependent variable and each continuous independent variable (denoted by $x$ below) in our principal model was transformed following Box and Cox (1964): $x^{(\lambda)}=\left(x^{\lambda}-1\right) / \lambda$. The linear additive model corresponds to $\lambda=1$ and the loglinear model corresponds to $\lambda=0$. A one-dimensional grid search was used to compute the maximum likelihood estimate of $\lambda$ (Judge et al., 1985, p. 841; Greene, 1993, p. 332). Lambda was systematically varied over the range - 1 to 1 in increments of 0.10 , and for each of the 21 values of $\lambda$, concentrated log-likelihood function value was computed. In this formulation a ranking on the concentrated likelihoods is equivalent to a ranking on the model's variances (Judge et al., 1985). Linearity is tested by computing a likelihood ratio statistic treating $\lambda=1$ (for the linear additive model) or $\lambda=0$ (for the loglinear model) as a parametric restriction. Model Parameter restriction Chi-square statistic Linear additive: $\quad \lambda=1 \quad X^{2}(1)=21.30$ Loglinear: $\quad \lambda=0 \quad X^{2}(1)=2.92$

Thus, the linear additive model is rejected, but the loglinear model is not, providing empirical justification for the multiplicative model used in this study. 
In addition to departures from OLS assumptions about the error terms, we examine the data problems of multicollinearity and influential observations. The impact of influential observations is investigated using the criteria outlined in Belsley, Kuh, and Welsch (1980). Their procedures lead to the deletion of two observations from the regression. ${ }^{5}$ The re-estimated parameters, after omitting the influential observations, are presented in the right column of Table 6. The variation explained increases to nearly $90 \%$, but our principal results remain unchanged.

Multicollinearity is also expected to be a problem as all of the transactional variables and direct labor increase with the size of a plant's operations. The Belsley-Kuh-Welsch collinearity diagnostics, however, did not indicate a multicollinearity problem as the only index exceeding 20 did not have two variance components greater than 0.40 for the predictor variables. ${ }^{6}$ If severe multicollinearity is present, then coefficient estimates, although unbiased, are sensitive to minor model changes. The results for our principal model, however, persist across all our regressions with different variables or different model specification.

We do not have data on all the cost drivers used by our sample plants to allocate manufacturing overhead costs. Therefore, we cannot claim that the TRANSACT variables would enter the model significantly if we had time-series data for each plant and regressed $M O H$ (by plant) on its actual cost drivers and our TRANSACT variables. To explore this issue with our present data, we note that it is not uncommon for firms to allocate some $M O H$ using direct materials cost also as a cost driver. We estimated our regressions in Table 5 including direct materials cost as an additional independent variable. Individually and as a group the transactional variables remain significant when direct materials cost is included in addition to direct labor.

\footnotetext{
${ }^{5}$ In particular, $C O V, D F F I T S, h$, and RSTUDENT metrics are computed. An observation is identified as influential, and consequently omitted from the sensitivity test, if three or more of its computed diagnostic metrics exceed the cutoff values suggested in Belsley, Kuh, and Welsch (1980).

${ }^{6}$ The largest condition index is 37.56 with variance components of 0.89 (INTERCEPT) and 0.94 (DIRLAB). The next largest condition index is 15.06 .
} 
Direct materials cost itself is not significant in regressions (A), (B), (D), or (E), but is significant in regression $(\mathrm{C})$ when transactional variables are excluded.

Insert Table 7 Here

\section{Insert Table 8 Here}

An alternative specification of our model in Eq. (2) is obtained by scaling all the left-side and right-side variables by the log of total manufacturing costs. The results from the estimation of this scaled model in Table 7 also indicate a strong positive relation between transactions and overhead after controlling for volume. The regression in column (C) indicates no bivariate linear relation between the scaled overhead and scaled direct labor variables, but direct labor becomes significant when the scaled transactional variables are also included as in columns (A), (D), and (E). This result is consistent with Miller and Vollmann's thesis that direct labor has little power by itself to explain variation in $\mathrm{MOH}$ once the size effect is eliminated.

Finally we compare our results with those that would obtain if Foster and Gupta's partial correlation approach was used in this study. ${ }^{7}$ Recall from the discussion in Section 3 that if the transactional variables are uncorrelated after controlling for volume, FG's partial correlation test will tend to not reject the null hypothesis even when a transactional variable significantly influences overhead costs. The conservative bias of the FG partial correlation test is evident in our study when we replicate their approach. The results in Table 8 indicate that the FG test is not

\footnotetext{
${ }^{7}$ The sample size is reduced to 31 as one plant did not provide sales revenue information. Results reported in our Table 5 do not change appreciably when the models are estimated for this smaller sample.
} 
significant at the $1 \%$ level for any of the three transactional variables (AREAPP, PPPPER, $N E C O$ ) found to be significant in our multivariate regression analysis presented in Table 5 . The FG approach can also result in an upward bias. This is evidenced by the $Q U A L P E R$ variable, which is insignificant in the multivariate regression model, but appears to be significant (at the $5 \%$ level) when the partial correlation method is used.

\section{Concluding remarks}

There has been seemingly conflicting evidence to date on the relation between transactions reflecting production complexity and manufacturing overhead costs after controlling for volume. While Banker and Johnston (1993) found that measures of operational complexity are related to overhead costs in the airline industry, Foster and Gupta's (1990) analysis of manufacturing overhead costs for 37 plants of an electronics firm suggested little support for this relation. In this study we used data from 32 plants in the electronics, machinery, and automobile components industries to examine the association between manufacturing overhead costs and measures of transactions such as area per part, number of engineering change orders, and number of purchasing and production planning personnel. We document a strong relation between manufacturing overhead costs and these transactions for our sample of plants.

Our results suggest that plants striving to control their manufacturing costs may benefit from examining the impact their production strategies have on the types of transactions that drive overhead. To the extent that efficient manufacturing practices reduce production complexity, future research can help identify how transactions and manufacturing practices interact to affect overhead costs in different industries. This could provide a more complete specification of the 
process by which logistical, balancing, quality and change transactions drive overhead costs which, in turn, should help us understand how managerial actions to control activities can influence costs and productivity. 
Table 1. Comparison of sample plants and deleted observations.

Panel A: Plant size

\begin{tabular}{|c|c|c|c|c|c|c|}
\hline & \multicolumn{2}{|c|}{$\begin{array}{l}\text { Sample plants } \\
(n=32)\end{array}$} & \multicolumn{2}{|c|}{$\begin{array}{l}\text { Deleted observations } \\
(n=10)\end{array}$} & \multicolumn{2}{|c|}{ Test of difference } \\
\hline & Mean & Median & Mean & Median & Mean: $p(t)$ & Median: $p(z)$ \\
\hline $\begin{array}{l}\text { Plant space } \\
\text { (square feet) }\end{array}$ & 280,379 & 127,205 & 397,167 & 375,000 & 0.612 & 0.143 \\
\hline Employment & 457 & 365 & 1,247 & 528 & 0.009 & 0.453 \\
\hline
\end{tabular}

Panel B: Proportions by industry ${ }^{a}$

Sample plants

Deleted observations

$(n=32)$

$(n=10)$

Electronics

Machinery

Automobile components
0.20

0.50

0.30

a A chi-square test of homogeneity $\left(\chi^{2}(2)=2.91\right)$ cannot reject the hypothesis that the two sets of observations are from the same distribution $(p>0.20)$. 
Table 2. Manufacturing cost proportions by component $(n=32)$.

Panel A: Descriptive statistics of manufacturing costs

\begin{tabular}{lllll} 
& & \multicolumn{2}{c}{ Percentiles of distribution } \\
\cline { 3 - 4 } & Mean & $10 \%$ & $50 \%$ & $90 \%$ \\
\hline Direct labor & 0.089 & 0.030 & 0.065 & 0.191 \\
Direct material & 0.654 & 0.347 & 0.685 & 0.874 \\
MOH & 0.257 & 0.069 & 0.260 & 0.532 \\
\hline
\end{tabular}

Panel B: Mean components by industry

\begin{tabular}{lllll} 
& Electronics & Machinery & $\begin{array}{l}\text { Automobile } \\
\text { components }\end{array}$ & Foster \& Gupta \\
\hline Direct labor & 0.084 & 0.108 & 0.078 & 0.066 \\
Direct material & 0.652 & 0.636 & 0.675 & 0.543 \\
MOH & 0.264 & 0.256 & 0.247 & 0.391 \\
No. of observations & 15 & 8 & 9 & 37 \\
\hline
\end{tabular}


Table 3. Summary statistics $(n=32)$.

Panel A: Definition of variables and descriptive statistics $(n=32)$

\begin{tabular}{lrrrrr} 
& \multicolumn{5}{c}{ Percentiles of distribution } \\
\cline { 5 - 6 } Variable & \multicolumn{1}{c}{ Mean } & Std. dev. & \multicolumn{1}{c}{$10 \%$} & $50 \%$ & $90 \%$ \\
\hline MOH $(000$ 's) & $\$ 17,131.6$ & $\$ 18,541.1$ & $\$ 1,334.3$ & $\$ 10.360 .0$ & $\$ 37,148.0$ \\
AREAPP & 135.1 & 234.1 & 4.5 & 34.2 & 574.2 \\
PPPPER & 23.8 & 24.9 & 2.0 & 12.0 & 74.0 \\
QUALPER & 16.0 & 27.5 & 1.0 & 9.0 & 30.0 \\
NECO & 424.3 & 680.8 & 14.0 & 200.0 & $1,350.0$ \\
DIRLAB (000's) & $\$ 4,860.3$ & $\$ 5,306.5$ & $\$ 708.3$ & $\$ 3,781.9$ & $\$ 10,335.0$ \\
$P L T E Q P(000 ’ s)$ & $\$ 21,948.8$ & $\$ 19.809 .2$ & $\$ 2,239.9$ & $\$ 15,448.0$ & $\$ 58,892.3$ \\
NADMFN & 6.0 & 1.4 & 4 & 7 & 7
\end{tabular}

continued on next page 
Table 3 (continued)

Panel B: Descriptive statistics by industry

Means

\begin{tabular}{lcccc}
\cline { 2 - 4 } Variable & Electronics & Machinery & $\begin{array}{l}\text { Automobile } \\
\text { components }\end{array}$ & $p(F)$ \\
\hline MOH $(000$ 's) & $\$ 14,896$ & $\$ 26,403$ & $\$ 12,614$ & 0.259 \\
AREAPP & 54.9 & 175.4 & 232.7 & 0.184 \\
PPPPER & 32.8 & 21.0 & 11.2 & 0.110 \\
QUALPER & 23.7 & 9.9 & 8.7 & 0.342 \\
NECO & 366.6 & 909.0 & 89.4 & 0.036 \\
DIRLAB (000's) & $\$ 4,318$ & $\$ 7,477$ & $\$ 3,437$ & 0.260 \\
NADMFN & 6 & 6.6 & 5.4 & 0.210 \\
PLTEQP $(000$ 's) & $\$ 19,964$ & $\$ 20,740$ & $\$ 26,330$ & 0.745 \\
\hline
\end{tabular}

Medians

\begin{tabular}{lcccc}
\cline { 2 - 4 } Variable & Electronics & Machinery & $\begin{array}{l}\text { Automobile } \\
\text { components }\end{array}$ & $p\left(\chi^{2}\right)$ \\
\hline MOH $(000$ 's) & $\$ 11,007$ & $\$ 10,538$ & $\$ 9,086$ & 0.778 \\
AREAPP & 15.33 & 35.07 & 155.51 & 0.146 \\
PPPPER & 22 & 17 & 7 & 0.187 \\
QUALPER & 10 & 9 & 7 & 0.425 \\
NECO & 250 & 590 & 45 & 0.021 \\
DIRLAB (000's) & $\$ 4,000$ & $\$ 4,456$ & $\$ 2,670$ & 0.168 \\
NADMFN & 7 & 7 & 5 & 0.711 \\
PLTEQP $(000$ 's) & $\$ 9,580$ & $\$ 20,468$ & $\$ 18,794$ & 0.360 \\
\hline
\end{tabular}

$\mathrm{MOH}=$ annual manufacturing overhead costs in thousands of dollars,

$A R E A P P=$ square feet of shopfloor area per part,

PPPPER = number of purchasing and production planning personnel at the plant,

QUALPER = number of quality control and improvement personnel at the plant,

$N E C O=$ annual number of engineering change orders at the plant,

$D I R L A B=$ annual direct labor costs in thousands of dollars,

$P L T E Q P=$ net investment (book value) in plant and equipment in thousands of dollars,

$N A D M F N=$ number of administrative functions conducted at the plant. 
Table 4. Pearson (below the diagonal) and Spearman (above the diagonal) correlations $(n=32)$

\begin{tabular}{|c|c|c|c|c|c|c|c|c|}
\hline Variable & $\ln \mathrm{MOH}$ & In $A R E A P P$ & In PPPPER & $\ln Q U A L P E R$ & $\ln N E C O$ & $\ln D I R L A B$ & $\ln P L T E Q P$ & $\ln N A D M F N$ \\
\hline $\ln \mathrm{MOH}$ & 1.000 & $0.309^{*}$ & $0.782^{*}$ & $0.699^{*}$ & $0.449^{*}$ & $0.730^{*}$ & $0.645^{*}$ & $0.371^{*}$ \\
\hline In $A R E A P P$ & $0.380^{*}$ & 1.000 & -0.067 & 0.044 & -0.285 & $0.474^{*}$ & $0.467^{*}$ & $-0.331^{*}$ \\
\hline In PPPPER & $0.752^{*}$ & -0.044 & 1.000 & $0.765^{*}$ & $0.438^{*}$ & $0.443^{*}$ & $0.479^{*}$ & $0.438^{*}$ \\
\hline $\ln Q U A L P E R$ & $0.688^{*}$ & -0.004 & $0.822^{*}$ & 1.000 & $0.305^{*}$ & $0.519^{*}$ & $0.505^{*}$ & 0.288 \\
\hline $\ln N E C O$ & $0.414^{*}$ & -0.218 & $0.389^{*}$ & $0.307^{*}$ & 1.000 & 0.184 & -0.088 & $0.397^{*}$ \\
\hline $\ln D I R L A B$ & $0.733^{*}$ & $0.391^{*}$ & $0.440^{*}$ & $0.536^{*}$ & 0.259 & 1.000 & $0.594^{*}$ & 0.149 \\
\hline $\ln P L T E Q P$ & $0.588^{*}$ & $0.381^{*}$ & $0.442^{*}$ & $0.438^{*}$ & -0.165 & $0.566^{*}$ & 1.000 & 0.082 \\
\hline $\ln N A D M F N$ & $0.399^{*}$ & -0.277 & $0.435^{*}$ & $0.408^{*}$ & $0.363^{*}$ & 0.162 & 0.063 & 1.000 \\
\hline
\end{tabular}

* Significant at 5\% (one-tail). 
Table 5. Parameter estimates relating overhead costs to volume and transactional variables $(t$-statistics in parentheses, $n=32)$

\begin{tabular}{|c|c|c|c|c|c|c|}
\hline Variables & $\begin{array}{l}\text { Coefficient } \\
\text { (pred. sign) }\end{array}$ & (A) & (B) & (C) & (D) & (E) \\
\hline INTERCEPT & $\begin{array}{l}\beta_{0} \\
(?)\end{array}$ & $\begin{array}{l}2.610^{*} \\
{[2.87]}\end{array}$ & $\begin{array}{l}4.877^{* *} \\
{[8.89]}\end{array}$ & $\begin{array}{l}1.914^{*} \\
{[1.44]}\end{array}$ & $\begin{array}{c}2.150^{*} \\
{[2.01]}\end{array}$ & $\begin{array}{r}1.379 \\
{[1.37]}\end{array}$ \\
\hline $\ln A R E A P P$ & $\begin{array}{l}\beta_{1} \\
(+)\end{array}$ & $\begin{array}{l}0.194^{* *} \\
{[3.55]}\end{array}$ & $\begin{array}{l}0.272^{* *} \\
{[4.97]}\end{array}$ & - & $\begin{array}{l}0.187^{* *} \\
{[3.34]}\end{array}$ & $\begin{array}{l}0.225^{* *} \\
{[4.29]}\end{array}$ \\
\hline ln PPPPER & $\begin{array}{l}\beta_{2} \\
(+)\end{array}$ & $\begin{array}{l}0.595^{* *} \\
{[4.09]}\end{array}$ & $\begin{array}{l}0.575^{* *} \\
{[3.47]}\end{array}$ & - & $\begin{array}{l}0.541^{* *} \\
{[3.39]}\end{array}$ & $\begin{array}{l}0.559^{* *} \\
{[4.12]}\end{array}$ \\
\hline $\ln Q U A L P E R$ & $\begin{array}{l}\beta_{3} \\
(+)\end{array}$ & $\begin{array}{r}0.009 \\
{[0.06]}\end{array}$ & $\begin{array}{r}0.187 \\
{[1.16]}\end{array}$ & - & $\begin{array}{r}0.017 \\
{[0.11]}\end{array}$ & $\begin{array}{r}-0.042 \\
{[-0.29]}\end{array}$ \\
\hline In NECO & $\begin{array}{l}\beta_{4} \\
(+)\end{array}$ & $\begin{array}{l}0.211^{* *} \\
{[2.68]}\end{array}$ & $\begin{array}{l}0.251^{* *} \\
{[2.82]}\end{array}$ & - & $\begin{array}{l}0.232 * * \\
{[2.79]}\end{array}$ & $\begin{array}{l}0.194^{* *} \\
{[2.64]}\end{array}$ \\
\hline In $D I R L A B$ & $\begin{array}{l}\beta_{5} \\
(+)\end{array}$ & $\begin{array}{l}0.386^{* *} \\
{[2.93]}\end{array}$ & - & $\begin{array}{l}0.904^{* *} \\
{[5.49]}\end{array}$ & $\begin{array}{l}0.328^{*} \\
{[2.19]}\end{array}$ & $\begin{array}{l}0.394^{* *} \\
{[3.23]}\end{array}$ \\
\hline In $P L T E Q P$ & $\begin{array}{l}\beta_{6} \\
(+)\end{array}$ & - & - & - & $\begin{array}{r}0.104 \\
{[0.86]}\end{array}$ & - \\
\hline $\ln N A D M F N$ & $\begin{array}{l}\beta_{7} \\
(+)\end{array}$ & - & - & - & - & $\begin{array}{l}0.793^{*} \\
{[2.24]}\end{array}$ \\
\hline MACHIND & $\begin{array}{l}\beta_{8} \\
(?)\end{array}$ & $\begin{array}{r}-0.017 \\
{[0.07]}\end{array}$ & $\begin{array}{r}0.161 \\
{[0.61]}\end{array}$ & $\begin{array}{r}-0.016 \\
{[-0.04]}\end{array}$ & $\begin{array}{r}0.015 \\
{[0.07]}\end{array}$ & $\begin{array}{r}-0.117 \\
{[-0.52]}\end{array}$ \\
\hline$A C M P I N D$ & $\begin{array}{l}\beta_{9} \\
(?)\end{array}$ & $\begin{array}{c}0.414^{*} \\
{[1.71]}\end{array}$ & $\begin{array}{r}0.427 \\
{[1.55]}\end{array}$ & $\begin{array}{r}-0.053 \\
{[-0.14]}\end{array}$ & $\begin{array}{r}0.330 \\
{[1.25]}\end{array}$ & $\begin{array}{r}0.383 \\
{[1.70]}\end{array}$ \\
\hline $\begin{array}{l}\text { Adjusted } R^{2} \\
P(M O D E L) \\
P(T R A N S A C T)^{\mathrm{a}}\end{array}$ & & $\begin{array}{l}0.8271 \\
0.0001 \\
0.0001\end{array}$ & $\begin{array}{l}0.7745 \\
0.0001 \\
0.0001\end{array}$ & $\begin{array}{l}0.4890 \\
0.0001 \\
-\end{array}$ & $\begin{array}{l}0.8249 \\
0.0001 \\
0.0001\end{array}$ & $\begin{array}{l}0.8519 \\
0.0001 \\
0.0001\end{array}$ \\
\hline
\end{tabular}

* Significant at $5 \%$, one-tail; ${ }^{* *}$ significant at $1 \%$, one-tail.

${ }^{2}$ TRANSACT: $\beta_{1}=\beta_{2}=\beta_{3}=\beta_{4}=0$. 
Table 6. Parameter estimates with alternative estimation methods relating overhead costs to volume and transactional variables $(t$ statistics in parentheses, $n=32$ )

\begin{tabular}{|c|c|c|c|c|c|}
\hline Variables & $\begin{array}{l}\text { Coefficient } \\
\text { (pred. sign) }\end{array}$ & $\begin{array}{l}\text { Least } \\
\text { absolute } \\
\text { error }\end{array}$ & $\begin{array}{l}\text { White's } \\
\text { adjustment }\end{array}$ & $\begin{array}{l}\text { Rank } \\
\text { transform } \\
\text { regression }\end{array}$ & $\begin{array}{l}\text { Outliers } \\
\text { deleted } \\
(n=30)\end{array}$ \\
\hline INTERCEPT & $\begin{array}{l}\beta_{0} \\
(?)\end{array}$ & $\begin{array}{l}2.556^{* *} \\
{[2.19]}\end{array}$ & $\begin{array}{l}2.611^{* *} \\
{[4.54]}\end{array}$ & $\begin{array}{c}-7.736^{* *} \\
{[-3.11]}\end{array}$ & $\begin{array}{l}0.288^{* *} \\
{[4.07]}\end{array}$ \\
\hline In $A R E A P P$ & $\begin{array}{l}\beta_{1} \\
(+)\end{array}$ & $\begin{array}{l}0.201^{* *} \\
{[2.85]}\end{array}$ & $\begin{array}{l}0.194^{* *} \\
{[6.13]}\end{array}$ & $\begin{array}{l}0.222^{*} \\
{[2.23]}\end{array}$ & $\begin{array}{l}0.190^{* *} \\
{[4.40]}\end{array}$ \\
\hline In PPPPER & $\begin{array}{l}\beta_{2} \\
(+)\end{array}$ & $\begin{array}{l}0.602^{* *} \\
{[3.22]}\end{array}$ & $\begin{array}{l}0.595^{* *} \\
{[6.16]}\end{array}$ & $\begin{array}{l}0.538^{* * *} \\
{[4.33]}\end{array}$ & $\begin{array}{l}0.627^{* *} \\
{[5.53]}\end{array}$ \\
\hline $\ln Q U A L P E R$ & $\begin{array}{l}\beta_{3} \\
(+)\end{array}$ & $\begin{array}{r}0.083 \\
{[0.42]}\end{array}$ & $\begin{array}{r}0.009 \\
{[0.07]}\end{array}$ & $\begin{array}{r}0.053 \\
{[0.44]}\end{array}$ & $\begin{array}{r}0.038 \\
{[0.32]}\end{array}$ \\
\hline In $N E C O$ & $\begin{array}{l}\beta_{4} \\
(+)\end{array}$ & $\begin{array}{c}0.188^{*} \\
{[1.86]}\end{array}$ & $\begin{array}{l}0.211^{* *} \\
{[3.72]}\end{array}$ & $\begin{array}{l}0.269^{* *} \\
{[2.78]}\end{array}$ & $\begin{array}{l}0.247^{* *} \\
{[4.00]}\end{array}$ \\
\hline In $D I R L A B$ & $\begin{array}{l}\beta_{5} \\
(+)\end{array}$ & $\begin{array}{l}0.376^{*} \\
{[2.22]}\end{array}$ & $\begin{array}{l}0.386^{* *} \\
{[3.61]}\end{array}$ & $\begin{array}{c}0.321^{*} \\
{[2.99]}\end{array}$ & $\begin{array}{l}0.309^{* *} \\
{[2.99]}\end{array}$ \\
\hline $\ln M A C H I N D$ & $\begin{array}{l}\beta_{6} \\
(?)\end{array}$ & $\begin{array}{r}0.128 \\
{[0.42]}\end{array}$ & $\begin{array}{r}0.017 \\
{[0.07]}\end{array}$ & $\begin{array}{r}0.683 \\
{[0.38]}\end{array}$ & $\begin{array}{r}0.055 \\
{[0.27]}\end{array}$ \\
\hline$A C M P I N D$ & $\begin{array}{l}\beta_{7} \\
(?)\end{array}$ & $\begin{array}{r}0.341 \\
{[1.09]}\end{array}$ & $\begin{array}{l}0.414^{*} \\
{[2.12]}\end{array}$ & $\begin{array}{l}3.219^{*} \\
{[1.71]}\end{array}$ & $\begin{array}{l}0.498 * * \\
{[2.65]}\end{array}$ \\
\hline Adjusted $R^{2}$ & & - & 0.8271 & 0.8299 & 0.8932 \\
\hline$P(M O D E L)$ & & 0.0001 & 0.0001 & 0.0001 & 0.0001 \\
\hline$P(T R A N S A C T)^{a}$ & & 0.0001 & 0.0001 & 0.0001 & 0.0001 \\
\hline
\end{tabular}

*Significant at $5 \%$, one-tail; ** significant at $1 \%$, one-tail.

${ }^{a} T R A N S A C T: \beta_{1}=\beta_{2}=\beta_{3}=\beta_{4}=0$. 
Table 7. Parameter estimates relating overhead costs to volume and transactional variables after scaling all variables by log of total manufacturing costs ( $t$-statistics in parentheses, $n=32)$

\begin{tabular}{|c|c|c|c|c|c|c|}
\hline Variables & $\begin{array}{l}\text { Coefficient } \\
\text { (pred. sign) }\end{array}$ & (A) & (B) & (C) & (D) & (E) \\
\hline INTERCEPT & $\begin{array}{l}\beta_{0} \\
(?)\end{array}$ & $\begin{array}{c}0.313^{*} \\
{[1.90]}\end{array}$ & $\begin{array}{l}0.624^{* *} \\
{[9.50]}\end{array}$ & $\begin{array}{l}0.664^{* *} \\
{[4.72]}\end{array}$ & $\begin{array}{r}0.209 \\
{[1.09]}\end{array}$ & $\begin{array}{l}0.244^{*} \\
{[1.71]}\end{array}$ \\
\hline $\ln A R E A P P$ & $\begin{array}{l}\beta_{1} \\
(+)\end{array}$ & $\begin{array}{l}0.132^{*} \\
{[2.38]}\end{array}$ & $\begin{array}{l}0.119^{*} \\
{[2.03]}\end{array}$ & - & $\begin{array}{l}0.142^{* *} \\
{[2.52]}\end{array}$ & $\begin{array}{l}0.195^{* *} \\
{[3.77]}\end{array}$ \\
\hline In PPPPER & $\begin{array}{l}\beta_{2} \\
(+)\end{array}$ & $\begin{array}{l}0.381^{*} \\
{[1.74]}\end{array}$ & $\begin{array}{r}0.117 \\
{[0.63]}\end{array}$ & - & $\begin{array}{c}0.388^{*} \\
{[1.78]}\end{array}$ & $\begin{array}{l}0.396^{*} \\
{[2.11]}\end{array}$ \\
\hline In $Q U A L P E R$ & $\begin{array}{l}\beta_{3} \\
(+)\end{array}$ & $\begin{array}{r}-0.031 \\
{[-0.17]}\end{array}$ & $\begin{array}{r}0.147 \\
{[0.87]}\end{array}$ & - & $\begin{array}{r}-0.024 \\
{[-0.13]}\end{array}$ & $\begin{array}{r}-0.027 \\
{[-0.17]}\end{array}$ \\
\hline $\ln N E C O$ & $\begin{array}{l}\beta_{4} \\
(+)\end{array}$ & $\begin{array}{l}0.246^{* *} \\
{[2.96]}\end{array}$ & $\begin{array}{l}0.273^{* *} \\
{[3.13]}\end{array}$ & - & $\begin{array}{l}0.267^{* *} \\
{[3.13]}\end{array}$ & $\begin{array}{l}0.181^{*} \\
{[2.44]}\end{array}$ \\
\hline $\ln D I R L A B$ & $\begin{array}{l}\beta_{5} \\
(+)\end{array}$ & $\begin{array}{l}0.385^{*} \\
{[2.03]}\end{array}$ & - & $\begin{array}{r}0.259 \\
{[1.40]}\end{array}$ & $\begin{array}{l}0.338^{*} \\
{[1.74]}\end{array}$ & $\begin{array}{c}0.284^{*} \\
{[1.71]}\end{array}$ \\
\hline $\ln P L T E Q P$ & $\begin{array}{l}\beta_{6} \\
(+)\end{array}$ & - & - & - & $\begin{array}{r}0.140 \\
{[1.05]}\end{array}$ & - \\
\hline $\ln N A D M F N$ & $\begin{array}{l}\beta_{7} \\
(+)\end{array}$ & - & - & - & - & $\begin{array}{l}0.934^{* *} \\
{[3.12]}\end{array}$ \\
\hline MACHIND & $\begin{array}{l}\beta_{8} \\
(?)\end{array}$ & $\begin{array}{r}-0.014 \\
{[-0.62]}\end{array}$ & $\begin{array}{r}-0.012 \\
{[-0.49]}\end{array}$ & $\begin{array}{r}-0.007 \\
{[-0.26]}\end{array}$ & $\begin{array}{r}-0.007 \\
{[-0.26]}\end{array}$ & $\begin{array}{r}0.029 \\
{[1.32]}\end{array}$ \\
\hline$A C M P I N D$ & $\begin{array}{l}\beta_{9} \\
(?)\end{array}$ & $\begin{array}{r}0.037 \\
{[1.43]}\end{array}$ & $\begin{array}{r}0.031 \\
{[1.14]}\end{array}$ & $\begin{array}{r}-0.011 \\
{[-0.42]}\end{array}$ & $\begin{array}{r}-0.011 \\
{[-0.42]}\end{array}$ & $\begin{array}{l}0.934^{* *} \\
{[3.11]}\end{array}$ \\
\hline $\begin{array}{l}\text { Adjusted } R^{2} \\
P(M O D E L) \\
P(T R A N S A C T)^{a}\end{array}$ & & $\begin{array}{l}0.3261 \\
0.0167 \\
0.0065\end{array}$ & $\begin{array}{l}0.2420 \\
0.0396 \\
0.0139\end{array}$ & $\begin{array}{r}-0.0243 \\
0.5287 \\
-\end{array}$ & $\begin{array}{l}0.3290 \\
0.0216 \\
0.0051\end{array}$ & $\begin{array}{l}0.3057 \\
0.0021 \\
0.0011\end{array}$ \\
\hline
\end{tabular}

* Significant at $5 \%$, one-tail; ${ }^{* *}$ significant at $1 \%$, one-tail.

'TRANSACT: $\beta_{1}=\beta_{2}=\beta_{3}=\beta_{4}=0$. 
Table 8. Foster-Gupta partial correlations between overhead costs and direct labor and transactional variables after controlling for revenue $(n=31)$

\begin{tabular}{ll}
\hline Variable & $\begin{array}{l}\text { Pearson partial correlation } \\
\text { with } \ln M O H\end{array}$ \\
\hline $\ln D I R L A B$ & $0.442^{* *}$ \\
$\ln A R E A P P$ & 0.248 \\
$\ln P P P P E R$ & 0.205 \\
$\ln Q U A L P E R$ & $0.317^{*}$ \\
$\ln N E C O$ & $0.326^{*}$ \\
\hline
\end{tabular}

*Significant at $5 \%$ (one-tail); ${ }^{* *}$ significant at $1 \%$ (one-tail).

Foster-Gupta partial correlation computation

Step 1. Regress log of overhead costs, log of direct labor and logs of transactional variables on log of plant revenue.

Step 2. Partial correlation between log of overhead costs and log of direct labor (or transactional) variable is the Pearson correlation between the residuals from their respective regressions on log of plant revenue described in step 1 above. 


\section{References}

Banker, R.D. and H.H. Johnston, 1993, An empirical study of cost drivers in the U.S. airline industry, The Accounting Review, July, 576-601.

Banker, R.D. and G. Potter, 1993, Economic implications of single cost driver systems, Journal of Management Accounting Research 5, 15-31.

Belsley, D.A., E. Kuh, and R.E. Welsch, 1980, Regression diagnostics (Wiley, New York, NY).

Box, G. and D. Cox, 1964, An analysis of transformations, Journal of the Royal Statistical Society, B 26, 211-243.

Cooper R., 1990, Implementing an activity-based cost system, Journal of Cost Management, Spring, 33-42.

Cooper, R. and R.S. Kaplan, 1987, How cost accounting systematically distorts product costs, in: W. Bruns and R. Kaplan, eds., Accounting \& management: Field study experiments (Harvard Business School Press, Boston, MA).

Cooper, R. and R.S. Kaplan, 1991, The design of cost management systems: Text, cases, and readings (Prentice-Hall, Englewood Cliffs, NJ).

Deming, W., 1986, Out of the crisis (Center for Advanced Engineering Study, MIT, Cambridge, MA).

Drucker, P., 1963, Managing for business effectiveness, Harvard Business Review, May/June, 53-60.

Foster, G. and M. Gupta, 1990, Manufacturing overhead cost driver analysis, Journal of Accounting and Economics, Jan., 309-337. 
Glesjer, H., 1969, A new test for heteroscedasticity, Journal of the American Statistical Association 325, 316-323.

Goldberger, A.S., 1964, Econometric theory (Wiley, New York, NY).

Goldberger, A.S., 1991, A course in econometrics (Harvard University Press, Cambridge, MA).

Greene, W.H., 1993, Econometric analysis, 2nd ed. (MacMillan, New York, NY).

Hayes, R.H. and K.M. Clark, 1985, Explaining observed productivity differentials between plants: Implications for operations research, Interfaces, Nov.-Dee., 3-14.

Hiromoto, T., 1988, Another hidden edge - Japanese management accounting, Harvard Business Review, July-Aug., 22-26.

Iman, R.L. and W.J. Conover, 1979, The use of the rank transform in regression, Technometrics, Nov., 499-509.

Johnson, H.T., 1988, Activity-based information: A blueprint for world class management accounting, Management Accounting, June, 23-30.

Johnson, H.T. and R.S. Kaplan, 1989, Relevance lost (Harvard Business School Press, Boston, MA).

Johnston, J., 1984, Econometric methods (McGraw-Hill, New York, NY).

Judge, G., C. Hill, W. Griffiths, T. Lee, and H. Lütkepol, 1985, The theory and practice of econometrics (Wiley, New York, NY).

Koenker, R. and G. Bassett, 1978, Regression quantiles, Econometrica, Jan., 33-50.

Miller, J.G. and T.E. Vollmann, 1985, The hidden factory, Harvard Business Review, Sept.-Oct., $142-150$. 
Noreen, E. and N. Soderstrom, 1994, Are overhead costs strictly proportional to activity? Evidence from hospital service departments, Journal of Accounting and Economics 17, 255-278.

Shank, J.K. and V. Govindarajan, 1988, The perils of cost allocation based on production volumes, Accounting Horizons, Dec., 71-79.

Shapiro, S.S. and M.B. Wilk, 1965, An analysis of variance test for normality, Biometrika, 591611.

Shephard, R., 1970, The theory of cost and production (Princeton University Press, Princeton, $\mathrm{NJ})$.

White, H., 1980, A heteroskedasticity-consistent covariance matrix estimator and a direct test for heteroskedasticity, Econometrica 4, 817-838. 